\title{
Comunicación Pública. Nuevos Desafíos para la Democracia. Mauricio Weibel Instituto de la Comunicación e Imagen Centro de Estudios de la Comunicación Universidad de Chile. 109 páginas
}

\author{
José Miguel LABRÍN
}

Las profundas transformaciones que los Estados latinoamericanos han experimentado durante la última década con miras a la consolidación democrática, implican el desafío de articular nuevas relaciones entre las decisiones de la gestión pública con las expectativas, demandas y reivindicaciones propias de los ciudadanos, y las necesidades multivariables de las lógicas del crecimiento.

Relevar la comunicación como un eje estratégico que supera con creces su uso en tanto marketing político, permite observar cómo las decisiones de lo público pueden situarse en el actual contexto como un elemento garante de la legitimidad de las acciones gubernamentales, desde una perspectiva donde la participación ciudadana y el reconocimiento de las particularidades territoriales, sociales y culturales inciden en la configuración de un nuevo contrato social.

En este escenario, la aparición del libro "Comunicación Pública. Nuevos Escenarios para la Democracia", del ex profesor del Instituto de la Comunicación e Imagen de la Universidad de Chile, Mauricio Weibel, constituye un esfuerzo por plantear aquellas dimensiones que inciden en el despliegue de procesos comunicacionales a partir no solo de categorías teóricas sino también en un campo operativo.

De esta manera, el libro de Weibel establece dos niveles que tienden a intersectarse. El primero de ellos hace referencia a un análisis funcional de la relación entre desarrollo y crecimiento económico y los mecanismos que establece -en un nivel estratégico- la comunicación pública. En este eje, resulta relevante la revisión de los modelos aplicados para la superación de la pobreza, apostando por una relectura en el marco de una economía "glocalizada" y donde las comunicaciones aparecen como un componente para el despliegue de los vectores de desarrollo.

En el segundo, en una perspectiva sistémica, la comunicación pública es observada como un código basal de las relaciones, atendiendo entonces su relevancia a la progresiva y mayor complejidad de las sociedades contemporáneas. Dicho escenario sería para Weibel un espacio de convergencias y sinergias, donde las políticas requieren de un uso estratégico de la comunicación para lograr generar el cambio esperado al interior de los múltiples sistemas sociales.

Con ello se establece un interesante marco conceptual de las comunicaciones públicas, orientado a un lector no avezado en las distinciones propias del campo, y cuya lectura permite un amplio recorrido que culmina con las dimensiones más prácticas de la gestión. En este despliegue se incorporan elementos no convencionales como la preocupación por la atención a la diversidad en las comunicaciones del Estado, principios de equidad y el diálogo entre las diferentes agendas. El cierre dado por la importancia de la 
planificación comunicacional en las organizaciones, deviene en un ejercicio de ejemplificación de los cruces anteriormente reseñados.

Finalmente, la disposición a modo de "manual" en la cual se estructura el libro de Weibel, complementa además los tradicionales textos de enseñanza en la materia: cada capítulo puede observarse como una unidad de formación, incorporando para ese objetivo fichas técnicas, bibliografías complementarias y alternativas de autoevaluación del aprendizaje. Con ello resulta un texto que sin dudas es un aporte nacional a la discusión sobre el rol estratégico de las comunicaciones y su potencial replicación en el resto de Latinoamérica. 